\title{
Effects of aging on nitrergic neurons in human striatum and subthalamic nucleus
}

\author{
Efeitos do envelhecimento sobre os neurônios nitrérgicos no estriado e núcleo \\ subtalâmico humano
}

Bruno Lopes dos Santos-Lobato1,4, Elaine Aparecida Del-Bel ${ }^{1,2,4}$, José Eymard Homem Pittella ${ }^{3}$, Vitor Tumas 1,4

\begin{abstract}
Nitric oxide (NO) is a major neurotransmitter associated with motor control in basal ganglia. Movement disorders, as essential tremor and Parkinson's disease, are more prevalent on aged individuals. We investigated the effects of aging on neuronal density and diameter/area of nitrergic neurons in samples of striatum (caudate and putamen) and subthalamic nucleus of 20 human brains from normal subjects, stained by histochemistry for NADPH-diaphorase and immunohistochemistry for neuronal NO synthase. Our data showed aging does not modify the neuronal density and size of nitrergic neurons in striatum and subthalamic nucleus. These findings suggest a lack of association between aging and morphologic changes on nitrergic neurons.
\end{abstract}

Keywords: nitric oxide, basal ganglia, striatum, subthalamic nucleus, aging.

\section{RESUMO}

O óxido nítrico (NO) é um importante neurotransmissor associado ao controle motor nos núcleos da base. Os distúrbios de movimento, como tremor essencial e a doença de Parkinson, são mais prevalentes em indivíduos idosos. Nós investigamos os efeitos do envelhecimento sobre a densidade neuronal e diâmetro/área dos neurônios nitrérgicos em amostras de estriado (caudado e putâmen) e núcleo subtalâmico de 20 encéfalos humanos de indivíduos normais, corados pela técnica histoquímica da NADPH-diaforase e imunohistoquímica para a sintase do NO neuronal. Nossos resultados mostraram que o envelhecimento não modifica a densidade neuronal e as dimensões dos neurônios nitrérgicos no estriado e núcleo subtalâmico. Estes achados sugerem uma falta de associação entre envelhecimento e mudanças morfológicas nos neurônios nitrérgicos.

Palavras-chave: óxido nítrico, núcleos da base, estriado, núcleo subtalâmico, envelhecimento.

Basal ganglia (BG) are complex structures responsible for motor control, motor learning, executive functions, behaviors and emotion ${ }^{1}$. This system is regulated by many neurotransmitters, including nitric oxide (NO), a gaseous molecule recently reported to be responsible for many essential physiologic processes, including signaling in central nervous system $^{2}$. NO is generated by neuronal NO synthase (nNOS) in neurons. After its synthesis in neuronal cells, NO diffuses to neighboring cells and binds to soluble guanylate cyclase, triggering signaling pathways which modulate synaptic activity and other function ${ }^{3.4}$. Nitrergic neurons are present in many regions of central nervous system, particularly in BG.
Striatum and subthalamic nucleus (STN) are nuclei which contain high densities of nitrergic cells. Striatum is the main input nucleus of BG and receives topographical excitatory projections from almost the entire cerebral cortex. A specific class of striatal GABAergic aspiny interneurons synthesizes $\mathrm{NO}^{5}$. STN is another crucial nucleus for indirect pathway of BG, and also receives cortical inputs through hyperdirect pathway. Messenger RNA of nNOS was detected in more than 95\% of subthalamic neurons ${ }^{6}$.

Presence of nNOS-expressing neurons in BG suggests nitrergic neurotransmitter system has a role on regulation of functions processed by these nuclei.

\footnotetext{
'Universidade de São Paulo, Faculdade de Medicina de Ribeirão Preto, Departamento de Neurociências e Ciências do Comportamento, Ribeirao Preto SP, Brazil; ¿Universidade de São Paulo, Faculdade de Odontologia de Ribeirão Preto, Departamento de Fisiologia, Ribeirao Preto SP, Brazil;

${ }^{3}$ Universidade de São Paulo, Faculdade de Medicina de Ribeirão Preto, Departamento de Patologia, Ribeirao Preto SP, Brazil;

«Universidade de São Paulo, Núcleo de Apoio à Pesquisa em Neurociência Aplicada, Ribeirão Preto SP, Brazil.

Correspondence: Vitor Tumas; FMRP/USP, Departamento de Neurociências e Ciências do Comportamento; Av. Bandeirantes, 3900;14049-900 Ribeirão Preto SP, Brasil; E-mail: tumasv@fmrp.usp.br

Conflict of interest: There is no conflict of interest to declare.

Support: Conselho Nacional de Desenvolvimento Científico e Tecnológico.

Received 08 January 2015; Received in final form 04 April 2015; Accepted 24 April 2015.
} 
Aging brain is related to morphological and functional changes, however, effects of aging on nitrergic neurons of the BG are not extensively studied. In this study, our objective was to analyze influence of aging on density and size of nitrergic neurons in human striatum and STN.

\section{METHOD}

\section{Subjects and sample collection}

Post-mortem brain samples were obtained from twenty adult individuals (i.e., ten individuals under 60 years of age and ten individuals over 60 years of age) who exhibited no clinical or pathological evidence of neurological or psychiatric disorders, brain death or HIV infection. Demographic and clinical data from subjects, such as age, gender, previous diseases, medications, agonic state before death, death-sample fixation interval (i.e., post-mortem interval), sample fixation-sample cryoprotection interval, and sample cryoprotection-sample freezing interval, were recorded. Tissue was collected at autopsy and was free of significant macroscopic pathological alterations, as indicated by hematoxylin-eosin and Nissl staining. Brains were cut into slices with a thickness of $0.5 \mathrm{~cm}$ and fixed in a solution of $4 \%$ paraformaldehyde in $0.1 \mathrm{M}$ phosphate buffer $(\mathrm{PB})(\mathrm{pH}$ 7.4) for 48 hours at $4^{\circ} \mathrm{C}$. Slices were immersed in $30 \%$ sucrose in PB at $4^{\circ} \mathrm{C}$ until sedimentation, frozen with isopentane and dry ice, and stored at $-80^{\circ} \mathrm{C}$. Samples from striatum and STN were cut with a cryostat to generate sections with a thickness of 30 $\mu \mathrm{m}$. Sections were serially collected in a cryoprotective solution until staining.

The study was approved by the Ribeirão Preto Medical School Ethic Committee, and tissue was kindly provided by Department of Pathology of Ribeirão Preto Medical School.

\section{NADPH-diaphorase histochemistry}

Sections of striatum were processed to visualize NADPH-diaphorase (NADPHd) enzymatic activity, which correlates with presence of nNOS in neurons, using a protocol adapted from Vincent and Kimura ${ }^{7.8}$. Free-floating sections were rinsed for 30 minutes in $\mathrm{PB}$ and subsequently incubated in a staining solution containing $0.1 \mathrm{M} \mathrm{PB}(\mathrm{pH}$ 8.0) with $0.3 \%$ Triton $X-100,1 \mathrm{mg} / \mathrm{ml}$ of $\beta-\mathrm{NADPH}$ (Sigma, Saint Louis, Missouri, U.S.A.) and $0.1 \mathrm{mg} / \mathrm{ml}$ of Nitroblue Tetrazolium (NBT) (Sigma). Incubation was performed in the dark at $37^{\circ} \mathrm{C}$ for 180 minutes. After incubation, sections were rinsed thoroughly in $\mathrm{PB}$, mounted onto gelatin-coated slides, and air-dried overnight. Sections were dehydrated with different grades of alcohol, and covered with Entellan mounting medium (MERK, Darmstadt, Germany).

\section{Immunohistochemistry}

NADPHd technique for STN sections showed poor staining, and use of immunohistochemistry was chosen to label nNOS, with a better signal-noise ratio. Following antigenic recovery and blocking with bovine serum albumin $2 \%$ (BSA - NGS; Jackson Immuno Research, U.S.A.), freefloating sections were incubated overnight with a 1:15,000 dilution of a sheep anti-nNOS antibody (kindly donated by Prof. Dr. Piers C. Emson, Babraham Institute, Cambridge, U.K.). To detect primary antibody, it was used rabbit anti-sheep biotinylated secondary antibody, at a dilution of 1:400 (Vector Laboratories; Burlingame, California, U.S.A.), incubated for 90 minutes. Secondary antibody was used in combination with an avidin-biotin-peroxidase complex for 120 minutes (Vector Laboratories) and 3,3'-diaminobenzidine for 10 minutes (Sigma). NADPHd staining was not performed on the same sections labeled by nNOS or NeuN immunohistochemistry.

\section{Analysis of striatum and subthalamic nucleus}

Striatum (i.e., caudate and putamen) was subdivided into 10 levels along the anteroposterior axis, from the most anterior portion of caudate to the most posterior portion of putamen, using the following coordinates, with anterior commissure as point zero ${ }^{11}$ : section $1,-20.0 \mathrm{~mm}$; section $2,-15.0 \mathrm{~mm}$; section 3, -10.0 mm; section 4, -5.8 mm; section 5, -2.0 mm; section $6,+2.0 \mathrm{~mm}$; section $7,+9.3 \mathrm{~mm}$; section $8,+14.6 \mathrm{~mm}$; section $9,+19.9 \mathrm{~mm}$; and section $10,+25.2 \mathrm{~mm}$. Caudate and putamen were also subdivided, using anterior commissure as a landmark, into three (i.e., precommisural head, postcommissural head and body of caudate) and two territories (i.e., precommissural and postcommissural putamen) respectively, as described previously.

STN was subdivided into 3 anteroposterior levels at specific coordinates ${ }^{9}$ : anterior: at the level of mammillary bodies, $+13.3 \mathrm{~mm}$; middle: next to $\mathrm{SN}$ pars compacta, $+16.0 \mathrm{~mm}$; and posterior: at the level of red nucleus, +18.6 $\mathrm{mm}$ ) and into three functional territories (i.e., sensorimotor, associative and limbic), based on method proposed by Parent and Hazrati ${ }^{10}$.

We examined sections with an Axiophot II microscope (Carl Zeiss, Jena, Germany) equipped with a 3.0 megapixel Axiocam MRc digital camera and a microcomputer with AxioVison LE software version 4.8.1.0 (Carl Zeiss MicroImaging GmbH, Oberkochen, Germany). Whole section image was scanned at high resolution and 100x magnification using "MosaiX" module of AxioVison LE software. Final rendering of each drawing was generated with Adobe Photoshop CS5 64-bit for Windows (Adobe Systems, San Jose, California, U.S.A.). Images were saved on a computer in TIFF format.

\section{Measurement of neuronal density and morphometric parameters}

Neuronal counts were performed manually, using a virtual grid (i.e., squares with an area of $1 \mathrm{~mm}^{2}$ ), which was created with ImageJ 64-bit image processor (National Institute 
of Health, U.S.A.), on image file. Grid squares were analyzed alternately, by a scanning method ${ }^{11}$. Counting was performed by a single investigator blinded to clinical data. Only neurons with clear boundaries and recognizable neuronal morphology were included. Neuronal density was defined as mean number of labeled neurons per square of a region or nucleus, and this value was represented as cell $/ \mathrm{mm}^{2}$. Some nitrergic neurons from striatum and STN were selected for measurement of area of soma $\left(\mu \mathrm{m}^{2}\right)$ and maximum diameter of soma $(\mu \mathrm{m})$. Approximately 40 neurons per brain in striatum and 24 neurons per brain in STN were analyzed for these morphometric parameters.

\section{Statistics}

All values were described as mean \pm SEM. T-test or Mann-Whitney test was used to compare two independent samples. Pearson's correlation coefficients were used to verify association between age and neuronal density. Differences were considered significant when $\mathrm{p}<0.05$.

\section{RESULTS}

NADPHd histochemical staining and immunohistochemical staining resulted in reliably stained nitrergic neurons in all studied brains. Pre- and post-mortem factors (i.e., agonic state before death and post-mortem intervals) did not influence nitrergic neuronal counts (backwise method; general linear model with all factors: $p=0.309$ ). Mean post-mortem interval was 9.3 hours (Table).
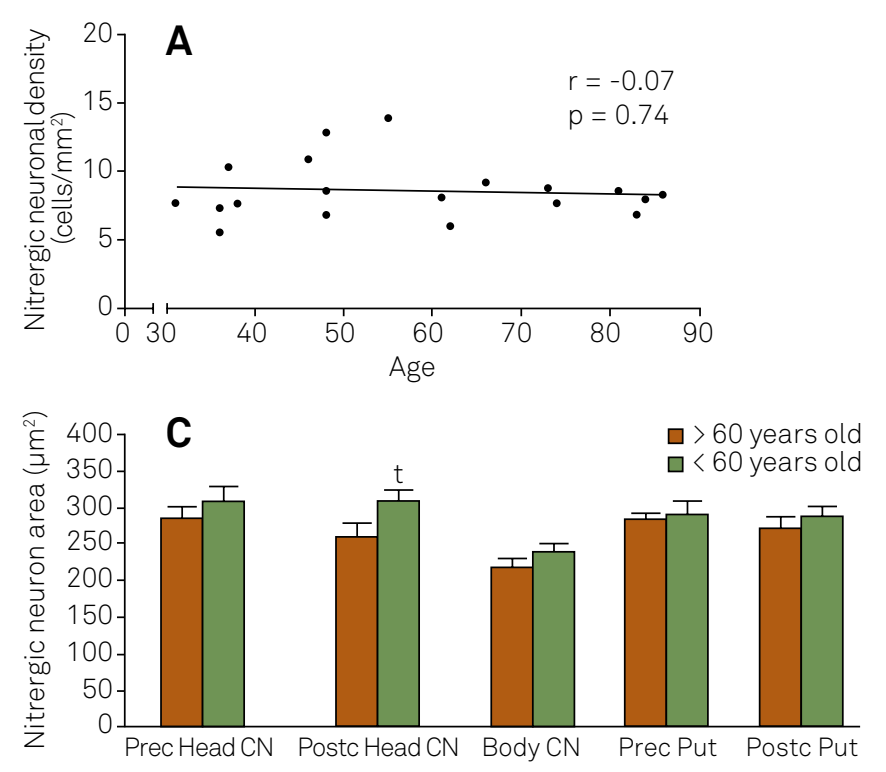

In striatum, there was no correlation between age and nitrergic neuronal density in caudate or putamen, and no difference on area/diameter of soma between $>60$ years-old and $<60$ years-old subjects (Figure 1).

In STN, there was no correlation between age and nitrergic neuronal density and no difference on area/diameter of soma between $>60$ years-old and $<60$ years-old subjects (Figure 2 ).

Table. Clinical data of patients. The mean PMI was 9.3 hours.

\begin{tabular}{lcccc}
\hline Case & Gender & $\begin{array}{c}\text { Age } \\
\text { (years) }\end{array}$ & $\begin{array}{c}\text { PMI } \\
\text { (hours) }\end{array}$ & Cause of death \\
\hline 1 & Female & 31 & 8.5 & Cardiac arrhytmia \\
2 & Male & 36 & 5 & Cardiac tamponade \\
3 & Male & 36 & 3.5 & Pneumonia \\
4 & Male & 37 & 11.5 & Bacterial meningitis \\
5 & Male & 38 & 16 & Upper gastrointestinal bleeding \\
6 & Female & 46 & 6 & Upper gastrointestinal bleeding \\
7 & Male & 48 & 10 & Upper gastrointestinal bleeding \\
8 & Female & 48 & 4 & Upper gastrointestinal bleeding \\
9 & Male & 53 & 5.5 & Upper gastrointestinal bleeding \\
10 & Male & 55 & 10 & Salmonellosis septic-toxic shock \\
11 & Male & 61 & 10 & Pulmonary edema \\
12 & Male & 61 & 5.5 & Peritonitis \\
13 & Male & 62 & 21.5 & Acute myocardial infarct \\
14 & Female & 66 & 14 & Ruptured thoracic aortic aneurysm \\
15 & Male & 73 & 5.5 & Abdominal abscess bleeding \\
16 & Male & 74 & 7 & Acute myocardial infarct \\
17 & Female & 81 & 7.5 & Septic shock due urinary tract infection \\
18 & Female & 83 & 12 & Multiple bleedings \\
19 & Male & 84 & 6 & Ruptured abdominal aortic aneurysm \\
20 & Female & 86 & 17 & Acute myocardial infarct \\
\hline
\end{tabular}

PMI: post-mortem interval.
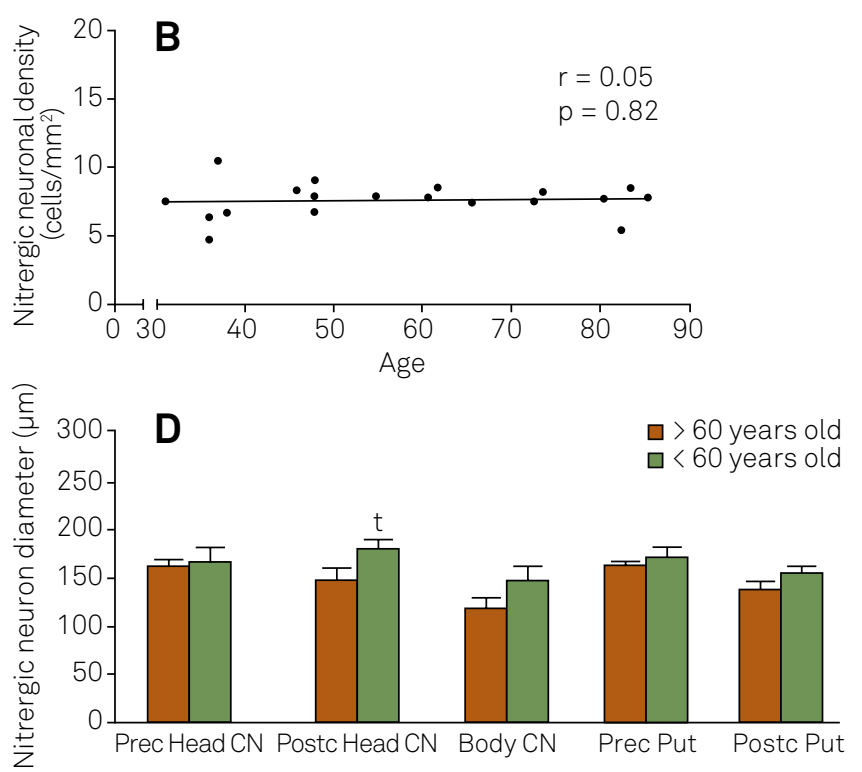

Body CN: body of caudate; Prec Head CN: precommissural head of caudate; Prec Put: precommissural putamen; Postc Head CN: postcommissural head of caudate; Postc Put: postcommissural putamen; PV Put: posteroventral putamen.

Figure 1. Effects of aging on neuronal density and morphology in striatum. Regression analysis between nitrergic neuronal density and age (in years) in caudate nucleus (A) and putamen (B). Histograms of nitrergic neuron area (C) and diameter (D) found within territories of striatum in young adults and aged individuals. ${ }^{\mathrm{t}}=\mathrm{p}$ between 0.05 and 0.1 . 

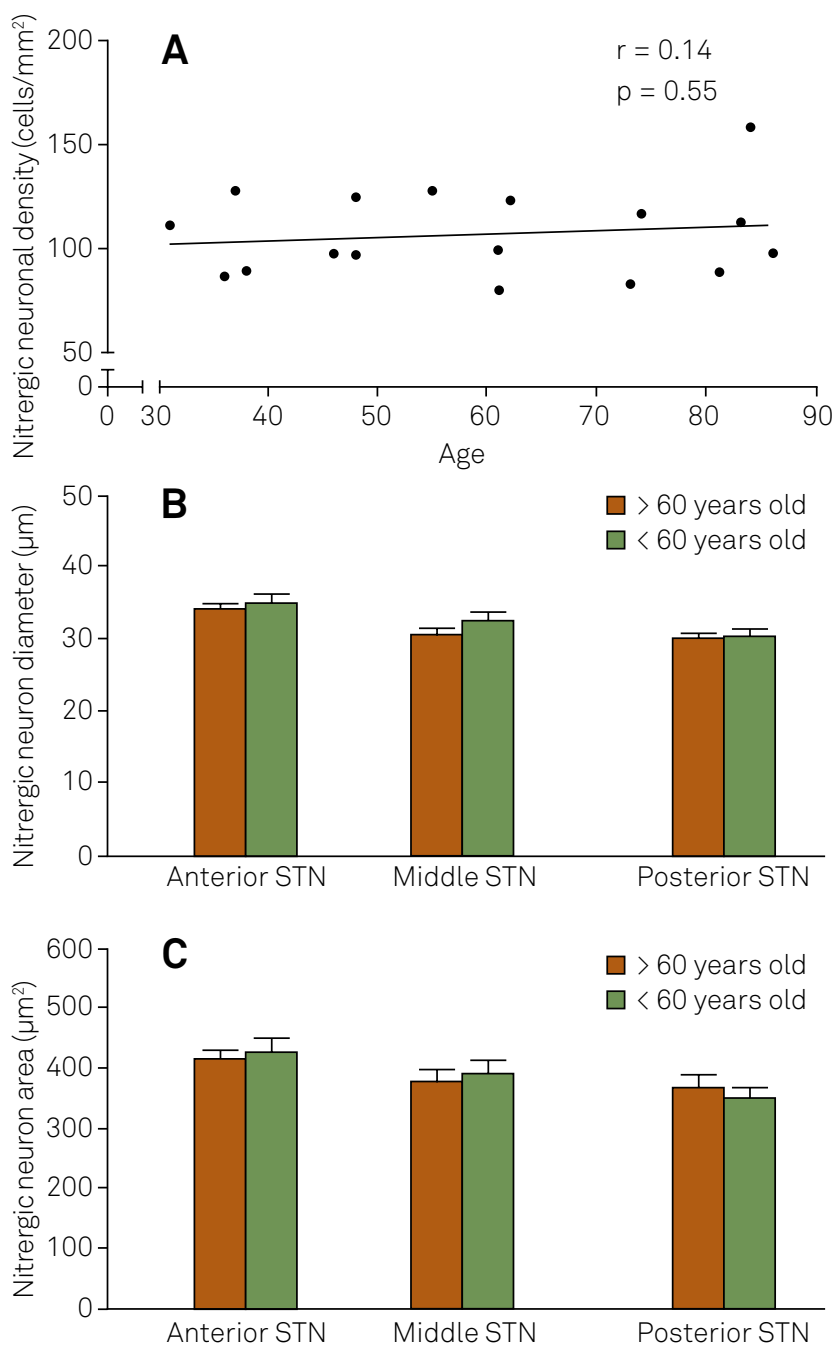

STN: subthalamic nucleus.

Figure 2. Effects of aging on neuronal density and morphology in subthalamic nucleus. Regression analysis between nitrergic neuronal density and age (in years) in subthalamic nucleus (A). Histograms of nitrergic neuron diameter (B) and area (C) found within territories of subthalamic nucleus in young adults and aged individuals.

\section{DISCUSSION}

Our study did not show any effect of aging on density and morphology of nitrergic neurons in human striatum and STN. Although a previous study had shown changes in neuronal density of the striatum and STN of aged rats, a work with human brains did not show any significant change on morphometric parameters with aging in striatum ${ }^{11,12}$.

Aging is associated with classic morphological changes on BG. Striatum and substantia nigra show reduction on its volumes, but a noteworthy loss of neurons is only seen on substantia nigra ${ }^{13}$. Age-related progressive atrophy on striatum is attributed to a combination of neuronal loss and reduction of neuronal area. There are few data about role of aging on STN, globus pallidus and pedunculopontine tegmental nucleus.

There are some evidences suggesting nitrergic neurons in human striatum may be less vulnerable to neurodegenerative process of Huntington's disease. Neuropathology of this disease shows a massive loss of medium spiny neurons and striatal atrophy which spares nNOS-expressing neurons ${ }^{14}$. Our results indicate nitrergic neurons may be resistant also to aging process.

Our study had some limitations. Regarding to counting issues, a two-dimensional method was chosen for cell counting, instead of a three-dimensional stereological and "unbiased" method, which could bring some doubt to validity of results. This option was done due the large volume of human striatum, high number of neurons counted, low variability in nitrergic neuron size and homogeneous pattern for neuronal distribution in striatum and STN. In these settings, both two-dimensional and three-dimensional cell-counting are capable of providing estimates of neuronal density of cells in brain and each approach has its own strengths, weaknesses and biases $^{14,15}$. Therefore, we must interpret these results carefully before assume a lack of causality between the aging process and morphologic changes on nitrergic neurons. Considering possible biases of a two-dimensional cell analysis, these data must be confirmed also by a three-dimensional-based study.

Furthermore, this study did not investigate subtle neuronal morphology (as the length and complexity of dendritic branching), recently associated with the process of brain aging ${ }^{16}$.

In conclusion, our results suggest aging does not change density and diameter/area of nitrergic neurons in human striatum and STN. Further works are needed to confirm absence of association between aging and nNOS-expressing neuronal density and size. These data are essential for a wider knowledge of BG circuitry, as well the modulation mediated by NO in striatum and STN and possible therapeutic interventions on neurological and psychiatric diseases involving the nitrergic neurotransmitter system.

\section{ACKNOWLEDGMENTS}

We would like to thank the Applied and Experimental Neurology Laboratory of Ribeirão Preto Medical School for image processing, to Mrs. Célia Aparecida da Silva and autopsy technicians for technical support.

\section{References}

1. Lanciego JL, Luquin N, Obeso JA, Functional neuroanatomy of the basal ganglia. Cold Spring Harb Perspect Med. 2012;2(12):a009621. doi:10.1101/cshperspect.a009621
2. Garthwaite J, Charles SL, Chess-Williams R. Endothelium-derived relaxing factor release on activation of NMDA receptors suggests role as intercellular messenger in the brain. Nature. 1988;336(6197):385-8. doi:10.1038/336385a0 
3. Benarroch EE. Nitric oxide: a pleiotropic signal in the nervous system. Neurology. 2011;77(16):1568-76. doi:10.1212/WNL.0b013e318233b3e4

4. Del-Bel E, Padovan-Neto FE, Raisman-Vozari R, Lazzarini M. Role of nitric oxide in motor control: implications for Parkinson's disease pathophysiology and treatment. Curr Pharm Des. 2011;17(5):471-88. doi:10.2174/138161211795164176

5. Bernácer J, Prensa L, Giménez-Amaya JM. Morphological features, distribution and compartmental organization of the nicotinamide adenine dinucleotide phosphate reduced-diaphorase interneurons in the human striatum. J Comp Neurol. 2005;489(3):311-27. doi:10.1002/cne.20616

6. Nisbet AP, Foster OJ, Kingsbury A, Lees AJ, Marsden CD. Nitric oxide synthase mRNA expression in human subthalamic nucleus, striatum and globus pallidus: implications for basal ganglia function. Brain Res Mol Brain Res. 1994;22(1-4):329-32. doi:10.1016/0169-328X(94)90062-0

7. Matsumoto T, Nakane M, Pollock JS, Kuk JE, Förstermann $U$. A correlation between soluble brain nitric oxide synthase and NADPH-diaphorase activity is only seen after exposure of the tissue to fixative. Neurosci Lett. 1993;155(1):61-4. doi:10.1016/0304-3940(93)90673-9

8. Vincent SR, Kimura H. Histochemical mapping of nitric oxide synthase in the rat brain. Neuroscience. 1992;46(4):755-84. doi:10.1016/0306-4522(92)90184-4

9. Mai K, Assheuer J, Paxinos G. Atlas of the human brain. London: Academic Press; 2004.
10. Parent A, Hazrati LN. Functional anatomy of the basal ganglia. I. The cortico-basal ganglia-thalamo-cortical loop. Brain Res Brain Res Rev. 1995;20(1):91-127. doi:10.1016/0165-0173(94)00007-C

11. Selden N, Geula C, Hersh L, Mesulam MM. Human striatum: chemoarchitecture of the caudate nucleus, putamen and ventral striatum in health and Alzheimer's disease. Neuroscience. 1994;60(3):621-36. doi:10.1016/0306-4522(94)90491-X

12. Cha Cl, Sohn SG, Chung YH, Shin C, Baik SH. Region-specific changes of NOS-IR cells in the basal ganglia of the aged rat. Brain Res. 2000;854(1-2):239-44. doi:10.1016/S0006-8993(99)02279-9

13. Fearnley JM, Lees AJ. Ageing and Parkinson's disease: substantia nigra regional selectivity. Brain. 1991;114(5):2283-301. doi:10.1093/brain/114.5.2283

14. Ferrante RJ, Kowall NW, Beal MF, Richardson EPJr, Bird ED, Martin JB. Selective sparing of a class of striatal neurons in Huntington's disease. Science. 1985;230(4725):561-3. doi:10.1126/science. 2931802

15. Matricon J, Bellon A, Frieling H, Kebir O, Le Pen G, Beuvon F et al. Neuropathological and Reelin deficiencies in the hippocampal formation of rats exposed to MAM: differences and similarities with schizophrenia. PloS One. 2010;5(4):e10291. doi:10.1371/journal.pone.0010291

16. Dickstein DL, Kabaso D, Rocher AB, Luebke JI, Wearne SL, Hof PR. Changes in the structural complexity of the aged brain. Aging Cell. 2007;6(3):275-84. doi:10.1111/j.1474-9726.2007.00289.x 